\title{
The pancreas as a target of metastasis from renal cell carcinoma: Results of surgical treatment in a single institution
}

\author{
Juan Glinka, Rodrigo Sanchez Claria, Victoria Ardiles, Eduardo de Santibañes, \\ Juan Pekolj, Martín de Santibañes, and Oscar Mazza
}

Department of General Surgery, Hepato-Bilio-Pancreatic Unit, Hospital Italiano de Buenos Aires, Buenos Aires, Argentina

\begin{abstract}
Backgrounds/Aims: Metastasis in the pancreatic gland is infrequent, representing between $2-5 \%$ of the tumors that affect this organ. However, secondary lesions of clear cell renal carcinoma (CCRC) can occur mainly in this location and it is frequently the only site of dissemination. Treatment of choice is resection in surgically fit patients, as it has been shown that it improves the quality of life and prognosis substantially. We retrospectively reviewed the clinical data of patients with pancreatic resections for metastatic CCRC since there are no reports of the treatment modality of this singular entity in Argentina. Methods: Retrospective cohort analysis over a 10-year period including eight patients who underwent pancreatic resection for metastatic CCRC. Results: $75 \%$ of patients were male with an average age of 65.5 years. The pancreatic surgery occurred at a median time of 9.2 years (1-24.8) from the renal operation. The pancreatic lesions were mostly solitary and asymptomatic. A pancreaticoduodenectomy (PD) was performed in 4 patients (50\%). Distal pancreatectomy (DP) was performed in 3 patients $(37.3 \%)$ and one patient $(12.5 \%)$ underwent a total pancreaticoduodenectomy. All the patients presented a confirmatory biopsy of pancreatic metastasis of CCRC. Complications were recorded in 3 patients $(42.85 \%)$. No intraoperative or postoperative mortality was registered. With a median follow-up of 45 months, three patients presented recurrence at 32,46 and 51 months, respectively. Only one patient showed death due to recurrence at 7.8 month. Conclusions: CCRC pancreatic metastases treated surgically have a low morbidity and mortality rate in high volume centers, showing excellent long-term survival. (Ann Hepatobiliary Pancreat Surg 2019;23:240-244)
\end{abstract}

Key Words: Clear renal cell carcinoma; Metastasis; Pancreas; Surgery

\section{INTRODUCTION}

Clear cell renal carcinoma (CCRC) is ranked 9th in cancer frequency worldwide, with approximately 63,990 new cases in 2017 in the United States. ${ }^{1}$ Around 20 to $30 \%$ of patients has metastases at the time of diagnosis. One-third of patients operated with curative intentions will develop local or distant recurrence over time. ${ }^{2}$ Although pancreatic metastases are usually rare, representing between 2 and $5 \%$ of the total of the neoplasms of the pancreas, this is an organ where CCRC secondary lesions mainly settle, and frequently as the only site of dissemination. They can appear in quite varying periods of time, with a range between 6 months and 7 years, being re- ported in the literature up to 32 years of the interval between nephrectomy and pancreatic metastases. ${ }^{3}$

The diagnosis is usually made through imaging studies such as computed tomography (CT) and magnetic resonance imaging (MRI) during the oncological follow-up of the CCRC since they are typically asymptomatic. However, depending on the location and size, they can manifest clinically with abdominal pain, digestive bleeding, jaundice, pancreatitis and weight loss. ${ }^{2,4}$ The treatment of choice for the single pancreatic metastasis is the resection in surgically fit patients. They are technically resectable in $80 \%$ of cases and have shown to substantially improve the quality of life and prognosis of these patients. ${ }^{5}$

There are some series of cases reported in the literature,

Received: October 22, 2018; Revised: May 5, 2019; Accepted: May 9, 2019

Corresponding author: Juan Glinka

Department of General Surgery, Hepato-Bilio-Pancreatic Unit, Hospital Italiano de Buenos Aires, Juan D. Perón 4190, Buenos Aires C1181ACH, Argentina

Tel: +54-11-4981-4501, Fax: +54-11-4981-4501, E-mail: juan.glinka@hospitalitaliano.org.ar

Copyright (C) 2019 by The Korean Association of Hepato-Biliary-Pancreatic Surgery

This is an Open Access article distributed under the terms of the Creative Commons Attribution Non-Commercial License (http://creativecommons.org/ licenses/by-nc/4.0) which permits unrestricted non-commercial use, distribution, and reproduction in any medium, provided the original work is properly cited. Annals of Hepato-Biliary-Pancreatic Surgery • pISSN: 2508-5778 • elSSN: 2508-5859 
but the treatment offered is often heterogeneous and the results published are very diverse. There are no reports either of the treatment modality of this singular entity in Argentina.

\section{MATERIALS AND METHODS}

We retrospectively reviewed clinical data of patients with pancreatic resections for metastatic tumors at the Department of General Surgery of Hospital Italiano de Buenos Aires (HIBA) from January 2005 to November 2015. Patients with pancreatectomy due to CCRC metastasis were selected.

Clinical data including sex, age, symptoms, medical history, time from initial (renal) surgery, operative outcomes and long-term survival were collected. Surgical pathology reports such as histological type, tumor size, number of lymph nodes, lymphatic invasion, and surgical margin status were considered.

Pancreatic resections were standard (pancreaticoduodenectomy, distal pancreatectomy with splenectomy or total pancreatectomy) in all cases. Only the lymph nodes in the specimen were evaluated, without performing extended lymphadenectomy.

Follow up information was obtained by retrospective analyses on medical reports and by direct contact with patients.

\section{RESULTS}

A total of 8 patients were included with a median age of 65.5 years (with a range of $46-82$ ). Six patients (75\%)

Table 1. Patients characteristics, number and size of nodules and symptoms

\begin{tabular}{cccccl}
\hline Patient & Sex & Age & $\begin{array}{c}\text { Number of } \\
\text { nodules }\end{array}$ & Size $(\mathrm{mm})$ & Symptoms \\
\hline 1 & $\mathrm{M}$ & 80 & 1 & 40 & \\
2 & $\mathrm{M}$ & 64 & 1 & 26 & Asymptomatic \\
3 & $\mathrm{M}$ & 82 & 1 & 20 & Asymptomatic \\
4 & $\mathrm{M}$ & 46 & 1 & 40 & Asymptomatic \\
5 & $\mathrm{M}$ & 58 & 1 & 25 & Asymptomatic \\
6 & $\mathrm{M}$ & 46 & 1 & 35 & Asymptomatic \\
7 & $\mathrm{~F}$ & 73 & 3 & $32 / 15 / 0.8$ & Asymptomatic \\
8 & $\mathrm{~F}$ & 67 & 5 & $37 / 1.5 / 1 /$ & Jaundice \\
& & & & $2.3 / 1.5$ & \\
\hline
\end{tabular}

M, Male; F, Female were male (Table 1).

All patients underwent left radical nephrectomy before the finding of the pancreatic lesion, except one patient who underwent right nephrectomy. The pancreatic surgery occurred at a median time of 9.2 years $(1-24.8)$ from the renal surgery.

A single patient clinically presented jaundice and multiple pancreatic metastatic nodules in imaging studies (Fig. 1). In the rest of the patients, the pancreatic lesions were solitary, asymptomatic and detected during the follow-up of the underlying disease.

The indicated follow-up study of the CCRC, and with which diagnosis of pancreatic metastasis was made, was a multislice computed tomography scan with intravenous contrast. In one patient, scintigraphy with somatostatin analog radiolabeled with 111 In (Indium) was requested due to diagnostic doubt about a primitive neuroendocrine tumor of the pancreas. Biopsies of lesions were not performed preoperatively.

A pancreaticoduodenectomy (PD) was performed in 4 patients $(50 \%)$ due to localized tumors in the head of the pancreas or in the uncinate process. Distal pancreatectomy (DP) was performed in 3 patients (37.3\%) with tumors in the body and tail of the pancreas. One patient (12.5\%) required total pancreaticoduodenectomy due to multiple pancreatic metastases. The approach of choice was the subcostal laparotomy in 7 patients $(87.5 \%)$ and midline laparotomy in 1 patient $(12.5 \%)$.

Of the $3 \mathrm{DPs}$, two were started laparoscopically and subsequently converted and concluded by conventional surgery, due to adhesions from previous renal surgery.

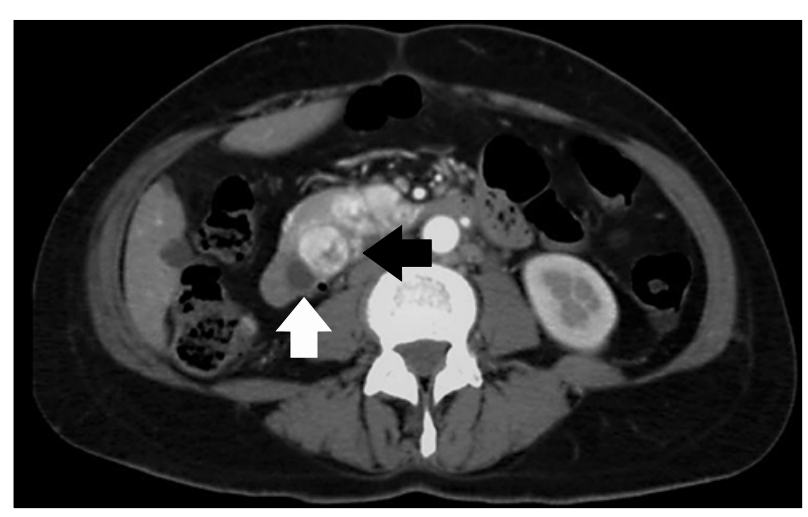

Fig. 1. CT scan showing multiple metastases from CCRC in the head of the pancreas. Note the hypervascular features in the arterial phase (black arrow) and the dilatated common bile duct (white arrow). 
All patients presented a confirmatory biopsy (by histology and immunohistochemistry) of pancreatic metastasis of CRCC (Fig. 2). The size and number of metastatic nodules in the biopsy specimens are summarized in Table 1.

One patient presented a posterior surgical margin of PD compromised by tumor (margin R1). In consequence, was treated with three-dimensional conformal radiation therapy delivered at 3 Grey / fraction up to 30 Grey in 10 fractions achieving stable local disease (no evidence of local recurrence). The rest of patients had free margins. The resected lymph nodes resulted in a 2-15 range. In all cases, the lymph nodes were negative for metastasis.

Complications were recorded in 3 patients (42.85\%). According to Dindo-Clavien (D-C) classification, ${ }^{6} 2$ patients were classified as grade IIIa: A patient during the

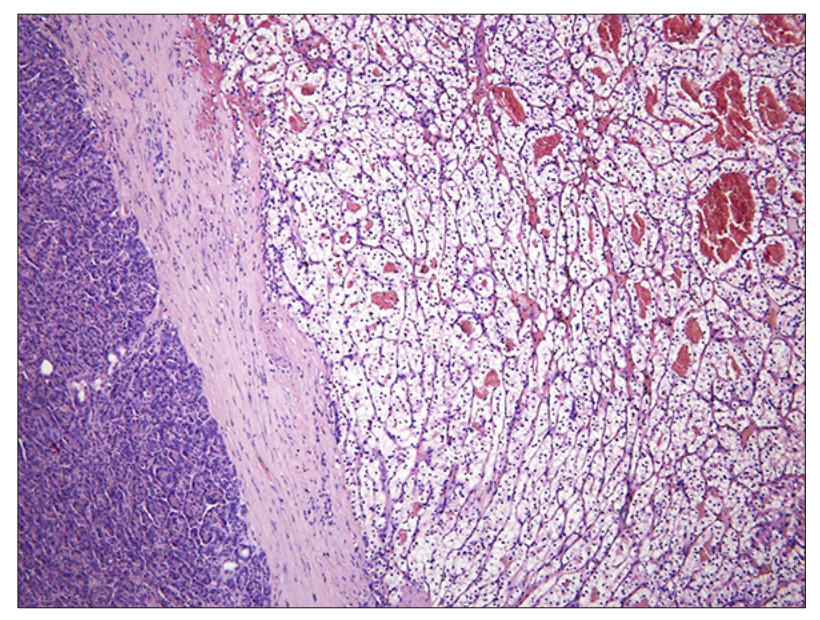

Fig. 2. Tumor proliferation, consisting of atypical cells with large clear cytoplasm and pronounced vascular proliferation (left) next to normal pancreatic parenchyma (right). Hematoxilyn/ Eosin stain $\times 100$. postoperative period of a PD developed a type B pancreatic fistula that required percutaneous drainage guided by CT-scan and one patient during the postoperative period of a DP that developed a pyogenic collection of the surgical site that needed the same treatment, which was sufficient and curative. The third patient with complications presented, in the postoperative period of a PD (DC-IV), acute abdominal bleeding, requiring surgical exploration twice. First exploration was on the sixth postoperative day, where the patient underwent an exploratory laparotomy with hemostasis of a mesenteric bleeding vessel. Second exploration was on day twelve: repeated acute abdominal bleeding was found where it was re-explored, and no evidence site of bleeding but necrotizing pancreatitis of the remaining pancreatic stump and dehiscence of pancreatico-jejunal anastomosis was observed, in which case, total pancreatectomy was completed. We did not register intraoperative or postoperative mortality. A median of 19 days was recorded for the hospital stay (range of 6-53 days).

With a median follow-up of 45 months, three patients presented recurrence at 32, 46 and 51 months, respectively. Only one patient showed death due to recurrence at 7.8 months (Table 2).

\section{DISCUSSION}

Metastases in the pancreas are infrequent, representing between $2 \%$ to $5 \%$ of tumors that affect this organ. Neoplasms that most commonly affect it secondarily include CCRC, melanoma, colorectal, breast cancer and sarcomas. Pancreatic involvement of these entities usually

Table 2. Metastasis localization, type of surgery, follow up, recurrence, survival and status

\begin{tabular}{clccccccc}
\hline Patient & $\begin{array}{c}\text { Localization } \\
\text { of metastasis }\end{array}$ & $\begin{array}{c}\text { Type of } \\
\text { surgery }\end{array}$ & $\begin{array}{c}\text { Kidney } \\
\text { RCC }\end{array}$ & $\begin{array}{c}\text { Years to } \\
\text { pancreatic } \\
\text { metastasis }\end{array}$ & Recurrence & $\begin{array}{c}\text { Time to } \\
\text { recurrence } \\
\text { (months) }\end{array}$ & $\begin{array}{c}\text { Survival } \\
\text { (months) }\end{array}$ & Status \\
\hline 1 & Head & PD & Left & 24 & No & - & 50 & Alive \\
2 & Head & PD & Left & 11 & Lung & 51 & 58 & Alive \\
3 & Body & DP & Left & 3 & No & - & 20 & Alive \\
4 & Body/tail & DP & Left & 3 & Bone & 32 & 38 & Alive \\
5 & Head & PD & Right & 15 & Brain/bone & 3 & 7.8 & Decesead \\
6 & Head & PD & Left & 1 & No & - & 29 & Alive \\
7 & Tail & DP & Left & 7 & Bone & 46 & 63 & Alive \\
8 & Diffuse & TP & Left & 18 & No & - & 17 & Alive \\
\hline
\end{tabular}

PD, pancreaticoduodenectomy; DP, distal pancreatectomy; TP, total pancreatectomy; RCC, renal cell carcinoma 
indicates disseminated oncological disease. ${ }^{7}$ Exception to the rule is the CCRC where a single metastases in the pancreas can exist in $50-73 \%$ of cases or multiple pancreatic metastases in 5-10\% (in some series up to $45 \%$ ) without affecting other organs. ${ }^{8}$ Regarding the latter, in our series, two patients presented multiple nodules, one of them radiologically observed as a single nodule. But, as explained in the work of Zerbi et al. ${ }^{4}$ such discordance can be found in up to $34.8 \%$ of patients.

Regarding presentation, according to the literature, we observed predominance in men (75\%) with an average age of 65.5 years. $^{9}$

It has been suggested that dissemination could be lymphatically, owing to the anatomical proximity of the kidneys to the pancreas in the retroperitoneal space. ${ }^{10}$ However, no relationship between laterality and location of the metastases has been demonstrated (the left-sided CCRC does not necessarily metastasize to the pancreas tail). The most accurate theory seems to be the hematogenous pathway, favored by the local conditions of the pancreatic parenchyma for the seating and proliferation of renal cancer lineage metastases (given that they can be multiple and exclusively pancreatic in up to $30 \%$ of cases) but must be confirmed with experimental works. ${ }^{5,11}$

In our series, almost all secondary lesions were imaging findings during the follow-up of the underlying disease, except one patient who started with jaundice (total and direct bilirubin values of 18 and $10 \mathrm{mg} / \mathrm{dl}$ ). However, in other series, up to $57 \%$ of cases can manifest clinically with abdominal pain, digestive bleeding, pancreatitis or weight loss depending on the location, size, and the number of metastatic nodules. ${ }^{12}$

Long-term follow-up (greater than 10 years) is mandatory in patients with CCRC history since the maximum interval observed between the renal surgery and the appearance of the pancreatic metastases in our series was of 24 years. In any case, there are reports of ranges of up to 32 years. $^{3}$

The diagnosis was made by multislice CT-scan with oral and endovenous contrast (including arterial and portal phase) requested in the oncological follow-up of the underlying disease. In $86 \%$, the initial finding consisted in a pancreatic image of variable size, with an intense enhancement during the arterial phase delimiting a central sector of cystic/necrotic degeneration. This central degen- eration is typically observed in metastatic nodules larger than 1.5 centimeters as we present. ${ }^{13}$

An abdominal MRI was complementarily used in 3 patients $(42.8 \%)$, to evaluate the pancreatic extension and number of lesions. In two patients, the metastasis presented as a pancreatic nodule with a hypointense signal in $\mathrm{T} 1$, hyperintense sectors in $\mathrm{T} 2$ and diffusion, and post-contrast enhancement in early phases. The remaining patient presented a hypointense focal image in $\mathrm{T} 1$ and isointense in $\mathrm{T} 2$, with no restriction in diffusion phase, being reported as of indeterminate origin. Scintigraphy with somatostatin analog radiolabeled with 111In (Indium) was used in a single patient with a 1.5 centimeters nodule, due to diagnostic uncertainty with regard to a neuroendocrine tumor, showing focal pancreatic uptake at the site of the tumor. It is known that this study can be positive also in the metastatic CCRC but if it is not, the diagnosis of metastasis is favored. ${ }^{14}$ In this case, the CCRC origin of the pancreatic nodule was confirmed in the histopathological study of the surgical specimen. Preoperative positron emission tomography has not been requested in any case due to its modest effectiveness, besides, it is not routinely recommended for CCRC staging. ${ }^{12}$ No preoperative biopsy was performed in our series, although it would be useful to use biliopancreatic echoendoscopy or percutaneous biopsy depending on the case, in inoperable patients, in order to have a histological sample and therefore guide the specific oncological treatment.

Regarding surgical approach for CCRC pancreatic metastases, Bassi et al. ${ }^{15}$ have shown a better survival and lower local recurrence with regulated resections, compared with atypical resections. Rückert et al. ${ }^{16}$ recommend an even more aggressive approach, which includes not only standard pancreatic resections but also a routine lymphadenectomy, although there are no systematic studies to support it.

In our work, the selected resections were standard pancreatectomies (pancreatoduodenectomy, distal pancreatectomy with splenectomy or total pancreatectomy), with analysis of lymph nodes included in the resected specimens without extending lymphadenectomy. In $62.5 \%$ of the cases, an average of 7 lymph nodes (range 2-15) was counted, in all cases negative for metastases. A characteristic of this entity according to Sellner F et al. the absence of lymph nodes metastases is a frequent implication in the 
pancreatic metastases of CCRC, and that would justify the good results of surgery. ${ }^{11}$

However, the presence of lymphatic metastases has been reported as a factor of poor prognosis. ${ }^{16}$

The complication rate was close to $40 \%$ in our study. It could be explained by the fact that most pancreatectomies were PDs, and they required a pancreatic anastomosis in a soft consistency pancreas. That fact, in addition to the presence of a thin Wirsung duct in those patients, favors the development of a subsequent pancreatic fistula and other related complications. Some reports highlight the rate of complications and mortality as a determining factor to indicate surgery. ${ }^{17}$ Fortunately, we did not register perioperative mortality in our series, and the complications registered in the current series were managed favorably. The mean hospital stay we recorded was 19 days, similar to that reported in the literature.

After pancreatic resection surgery, we considered a mean follow-up of 45 months of observation. In this period, 3 patients $(37.5 \%)$ had a recurrence at 32 months (single bone metastasis); 46 months (in the pulmonary hilum) and at 51 months (multiple bone metastases). In all cases, medical treatment was instituted with tyrosine kinase inhibitors, thus achieving control of the disease. Only one patient presented death due to disseminated recurrence (cerebral, bone and pulmonary) at 7.8 months, probably carrying a highly aggressive tumor biology. ${ }^{10}$

Currently, $50 \%$ of patients who underwent a pancreatic metastasis of CCRC resection in these series are alive and free of disease. Patients who had an extra-pancreatic recurrence after surgery had a minimum interval of 32 months free-disease survival. In any case, they have remained with stable disease at 45 -month follow-up average. This trend is comparable to the study by Schwarz et al. ${ }^{18}$ that has the longest follow-up in the treatment of this disease, where they have reported a global survival at 3-, 5-, and 10 years of 72,63 , and $32 \%$, respectively.

In conclusion, CCRC pancreatic metastases are infrequent, they usually do not present symptoms and appear after prolonged intervals of time after renal surgery, consequently demanding a lifetime follow-up. These, treated surgically in selected patients, have a low morbidity and mortality rates in high volume centers and have excellent results regarding long-term survival.

\section{REFERENCES}

1. Siegel RL, Miller KD, Jemal A. Cancer statistics, 2017. CA Cancer J Clin 2017;67:7-30.

2. Ballarin R, Spaggiari M, Cautero N, De Ruvo N, Montalti R, Longo $C$, et al. Pancreatic metastases from renal cell carcinoma: the state of the art. World J Gastroenterol 2011;17:4747-4756.

3. Thompson LD, Heffess CS. Renal cell carcinoma to the pancreas in surgical pathology material. Cancer 2000;89:1076-1088.

4. Zerbi A, Ortolano E, Balzano G, Borri A, Beneduce AA, Di Carlo V. Pancreatic metastasis from renal cell carcinoma: which patients benefit from surgical resection? Ann Surg Oncol 2008; 15:1161-1168.

5. Kusnierz K, Mrowiec S, Lampe P. Results of surgical management of renal cell carcinoma metastatic to the pancreas. Contemp Oncol (Pozn) 2015; 19:54-59.

6. Dindo D, Demartines N, Clavien PA. Classification of surgical complications: a new proposal with evaluation in a cohort of 6336 patients and results of a survey. Ann Surg 2004;240:205213.

7. Grassi P, Doucet L, Giglione P, Grünwald V, Melichar B, Galli $\mathrm{L}$, et al. Clinical impact of pancreatic metastases from renal cell carcinoma: a multicenter retrospective analysis. PLoS One 2016; 11:e0151662.

8. Lavu H, Yeo CJ. Metastatic renal cell carcinoma to the pancreas. Gastroenterol Hepatol (N Y) 2011;7:699-700.

9. Sohn TA, Yeo CJ, Cameron JL, Nakeeb A, Lillemoe KD. Renal cell carcinoma metastatic to the pancreas: results of surgical management. J Gastrointest Surg 2001;5:346-351.

10. Volk A, Kersting S, Konopke R, Dobrowolski F, Franzen S, Ockert D, et al. Surgical therapy of intrapancreatic metastasis from renal cell carcinoma. Pancreatology 2009;9:392-397.

11. Sellner F, Tykalsky N, De Santis M, Pont J, Klimpfinger M. Solitary and multiple isolated metastases of clear cell renal carcinoma to the pancreas: an indication for pancreatic surgery. Ann Surg Oncol 2006;13:75-85.

12. Moletta L, Milanetto AC, Vincenzi V, Alaggio R, Pedrazzoli S, Pasquali C. Pancreatic secondary lesions from renal cell carcinoma. World J Surg 2014;38:3002-3006.

13. Mueller-Lisse UG, Mueller-Lisse UL. Imaging of advanced renal cell carcinoma. World J Urol 2010;28:253-261.

14. Peter L, Sänger J, Hommann M, Baum RP, Kaemmerer D. Molecular imaging of late somatostatin receptor-positive metastases of renal cell carcinoma in the pancreas by 68Ga DOTATOC $\mathrm{PET} / \mathrm{CT}$ : a rare differential diagnosis to multiple primary pancreatic neuroendocrine tumors. Clin Nucl Med 2014;39:713-716.

15. Bassi C, Butturini G, Falconi M, Sargenti M, Mantovani W, Pederzoli P. High recurrence rate after atypical resection for pancreatic metastases from renal cell carcinoma. Br J Surg 2003;90: 555-559.

16. Rückert F, Distler M, Ollmann D, Lietzmann A, Birgin E, Teoule $\mathrm{P}$, et al. Retrospective analysis of survival after resection of pancreatic renal cell carcinoma metastases. Int J Surg 2016;26:6468.

17. Benhaim R, Oussoultzoglou E, Saeedi Y, Mouracade P, Bachellier $\mathrm{P}$, Lang H. Pancreatic metastasis from clear cell renal cell carcinoma: outcome of an aggressive approach. Urology 2015;85: 135-140.

18. Schwarz L, Sauvanet A, Regenet N, Mabrut JY, Gigot JF, Housseau E, et al. Long-term survival after pancreatic resection for renal cell carcinoma metastasis. Ann Surg Oncol 2014;21: 4007-4013. 